\title{
Castração, Esterilização, "Mudança" Artificial de Sexo.*
}

\author{
Antônio Chaves \\ Diretor da Faculdade de Direito da Uiversidade de \\ São Paulo (Brasil)
}

\begin{abstract}
SUmário: 1. A idéia da castraçāo quem a teve foi Semíramis. 2. Transexualismo e operações de "mudaņ̧a de sexo" 3 . O sindrome transexual e a lei. 4. Jurisprudência italiana em sentido negativo. 5. E em sentido positivo. 6. Situação no Brasil. 7. Será válido o casamento de quem tenha mudado de sexo?
\end{abstract}

\section{A idéia da castração quem a teve foi Semíramis}

Segundo a lenda, a castração foi introduzida pela belíssima SEMÍrAmis, rainha assíria fundadora de NINIVE e BABILÔNIA, a fim de eliminar heranças mórbidas, difundindo-se depois em todo o Oriente, Grécia e Roma.

Além da famosa lei racista alemã de 14.07.1933, a "esterilização dos anormais" começou a ser aplicada no Estado de Indiana a partir de 1907 e atualmente na maior parte dos Estados Unidos da América do Norte: em alguns, leis de esterilização de anormais, em outros de delinqüentes e em outros ainda, de ambos.

Por exigências eugênicas admite-se por toda a parte que possa ser necessária a castração e a esterilização, lícitas em pacientes e portadores de doenças incuráveis e transmissíveis, a fim de evitar descendência de degenerados e raquíticos.

$\mathrm{Na}$ Europa, a primeira lei foi promulgada em 1929 no Cantão de Vaud, Suíça. Do mesmo ano é a lei de esterilização da Dinamarca, seguindo o exemplo a Suécia.

\footnotetext{
* Conferência realizada em 25-3-1980 na Faculdade de Jurisprudência da Universidade de Roma, Instituto de Direito Privado.
} 
Em nenhum outro Estado, todavia, o problema assumiu as proporções da fndia. As autoridades, preocupadas com o índice alarmante de fome e de miséria, com 520 milhões de pessoas disputando uma porção diária de 200 gramas de arroz por pessoa, enquanto nascem diariamente 35.000 indianos, ritmo capaz de dobrar a população em 20 anos, começaram oferecendo um rádio portátil ou o equivalente em rupias para cada cidadão que se submetesse à operação de esterilização.

Não obtendo a campanha o êxito esperado, o governo decidiu realizá-la à força, obrigando os funcionários públicos e professores a indicar cada um, cinco "voluntários" sob pena de suspender seus ordenados ou demiti-los sumariamente.

O terror, ocasionado pelas sete milhões de esterilizações efetuadas em 1976, leva milhões de pessoas a se refugiarem nas florestas e transformou-se num problema político tão grave que influiu decididamente na derrota de Indira Gandhi nas eleições de março de 1977.

Aumenta todavia no mundo inteiro, o número de esterilizações voluntárias não só de homens como de mulheres, mesmo nos países onde tais operações são proibidas.

Segundo uma notícia proveniente de Roma e publicada pela imprensa mundial de 12.11.78, a esterilização voluntária feminina assumiu a posição de método de controle da natalidade mais difundido: cerca de 84 milhões de pessoas já o teriam utilizado e de acordo com as previsões, em 1985, mais de 200 milhões de casais o escolherão como o sistema mais eficaz para evitar filhos.

Todavia, o problema específico da castração assume aspecto de plena atualidade, como decorrência da mudança artificial de sexo.

\section{Transexualismo e operações de "mudança de sexo"}

A confirmação do fato que o sexo é um conceito plurivectorial, resultante de diferentes fatores: genéticos, sociais, psicológicos, encontra-se em casos de indivíduos que reúnem, no corpo, todas as características orgânicas de um determinado sexo, enquanto que seu psiquismo tende, irresistivelmente na direção do de sexo oposto.

Teremos então as hipóteses dos travestis ou fetichistas que sentem necessidade de usar roupas, atitudes e comple- 
mentos do sexo oposto ostentando a aparência do mesmo: homossexuais que se realizam somente com as pessoas do próprio sexo, e transexuais que possuem toda a disposição psíquica e afetiva de sexo contrário, mas não se conformam com a própria condição.

Por isso o comportamento deles é diferente: repudiam o sexo para o qual se apresentam "instrumentalmente" dotados, não só pelo seu comportamento, mas também biologicamente, usando como recurso extremo, quando o tratamento clínico não resulta eficaz, a providência da cirurgia, no esforço de viver normalmente integrados ao sexo psíquico ao qual sentem pertencer.

CAULDWELL, estudando em 1949 o estado psíquico do indivíduo cuja meta principal é a mudança de sexo, chamou-o de "síndrome de psicopatia transexual", expressão esta que viria a ser consagrada por HARRY BANJAMIM, e desde então usada por todos.

JACCUELINE PETIT, num estudo completo: "L'ambiguité du Droit Face au Syndrome Transsexuel", Revue Trimestrielle de Droit Civil, 1976, recorda a "bomba" que estourou na imprensa mundial nos primeiros dias de dezembro de 1952: a cirurgia à qual se submeteu o ex-soldado e combatente americano George Jorgensen, para "passar" ao sexo feminino, assumindo o nome de Christine. O autor da operação, CHISTIAN HAMBURGER, anunciou que o problema da conversão sexuaí estava definitivamente resolvido em todos seus aspectos plásticos, anatômicos, sexuais e psicológicos.

Recebeu 465 cartas, em dinamarquês, holandês, inglês, francês, alemão, italiano, norueguês, português, espanhol e sueco, com base nas quais escreveu um minucioso relatório.

\section{O síndrome transexual e a lei}

Segundo a Lei sueca de 21.04 .72 , relativa à determinação do sexo em certos casos, parágrafo 1: aquele que, transcorrida a juventude, demonstra não pertencer ao sexo no qual é registrado, que se comporta há muito tempo desta maneira e que se possa presumir que assim viverá para o futuro neste rol sexual, poderá, a seu pedido, obter a verificação de que pertence ao outro sexo. Semelhante comprovação é lícita, independentemente do fato da pertinência sexual do solicitante tenha sido precedentemente verificada em conformidade com o § 2 . 
A verificação, segundo o $\S 1$, não é lícita a menos que o requerente que tenha completado 18 anos, tenha sido esterilizado ou seja incapaz de procriar por outras razões.

$\S 20^{\circ}$. Aquele que tenha tais deformidades em seus órgãos genitais que levantem dúvidas quanto ao seu sexo, pode requerer sua verificação segundo o $\S 1$, contanto que isto seja compatível com o desenvolvimento dos órgãos sexuais e se uma correção das deformidades possa ser efetuada de modo que os órgãos sexuais correspondam melhor ao sexo desejado, ou se, não sendo desejável a correção, a atribuição de sexo corresponda melhor à constituição física geral do requerente.

Aquele que tiver 18 anos completos, ou que, mais jovem, não esteja mais sob tutela, deve pessoalmente requerer segundo o $\S 1$. Nos outros casos, o pedido deve ser feito pelo tutor. Se o requerimento diz respeito a jovem com mais de 12 anos, a verificação não será lícita a não ser com o consentimento do mesmo.

$\S 3 .^{\circ}$. A verificação segundo os $\S \S 10^{\circ}$ e $20^{\circ}$ só poderá ser solicitada por cidadão sueco não casado.

$\S 4 .^{\circ}$. Quem quer que pense solicitar a verificação na conformidade dos $\S \S 1 .^{\circ}$ e $2 .^{\circ}$ só poderá obter uma intervenção em seus órgãos genitais após autorização especial, com a finalidade de adaptá-los ao sexo oposto. A autorização só poderá ser concedida quando estejam reunidas as condições para obtenção da verificação.

$O$ pedido de autorização deve ser feito por quem requer a verificação. Será aplicável a determinação do $\S 2 .^{\circ}$, alínea 2 , frase 3.

Se até o momento da concessão de autorização, não for indicado nenhum médico, a intervenção será feita em hospital por um médico funcionário do mesmo.

Existem prescrições especiais para a esterilização e a castração.

$\S 5 .^{\circ}$. A questão da verificação de acordo com os $\S \S 10^{\circ}$ e $2 .^{\circ}$ ou da autorização, na conformidade do $\S 4 .^{\circ}$, será resolvida pela autoridade social suprema (Socialstyrelsen).

$\S 6 .{ }^{\circ}$. Contra as decisões da autoridade social poder-se-á recorrer ao tribunal administrativo.

§ 7.․ Quem estiver envolvido em negócio previsto por esta lei, não poderá pronunciar-se, sem autorização, sobre aquilo que venha a conhecer sobre a vida particular do inte- 
ressado. Quem transgredir conscientemente ou por negligência será punido com multa ou deençło até um ano. O ato de citação só será apresentado a pedido da vítima ou se o interesse público exigir uma ação penal.

$\S 80^{\circ}$ Quem, contrariamente a esta lei, pratique cientemente e por negligência na conformidade do $\S 4 .^{\circ}$, será punido com multa e pena de detenção de até seis meses, se o fato não for punido segundo o Código Penal.

A lei alemã de 15-8-1969 sobre a castração voluntária e outros métodos terapêuticos, dispõe no $\S 2 .^{\circ}$, que a mesma não é suscetível de ser reprimida penalmente, se este tratamento a juízo da ciência médica, for indicado para prevenir, sarar ou aliviar a pessoa de doenças, perturbações ou sofrimento psíquicos graves ligados à sexualidade anormal. $O$ interessado deve ter 25 anos e manifestar um consentimento livre e esclarecido sobre o ato terapêutico oferecido, após informação sobre a natureza e gravidade dos riscos inerentes à operação.

A lei dinamarquesa de 11-5-1935 permite a castração voluntária de pessoas cujos instintos sexuais anormais apresentem o risco de impelí-las ao crime, à decadência física, ou a graves sofrimentos morais. A transformação só pode ocorrer com a autorização do Ministério da Justiça e após um balanço clínico e endocrínico. O tratamento só é acessível aos dinamarqueses e só é praticado quando as conseqüências sejam suscetíveis de serem reconhecídas no plano jurídico.

A lei norueguesa de 1-6-1934, admite explicitamente a esterilização de qualquer adulto cujo requerimento tenha por base uma "razão séria" O médico avalia somente a capacidade e o valor do consentimento do interessado e pode recorrer também à castração.

Na Suíça a liceidade da operação fundada na finalidade terapêutica foi proclamada pelo Tribunal de Cantão de Neuchâtel em 2-7-1945.

A esterilização praticada fora das indicações médicas é tolerada por acordo tácito entre médicos e autoridades mesmo sem qualquer texto oficial.

\section{Jurisprudência italiana em sentido negativo}

Na Itália Pietro Perlingieri, La personalitá umana nell' ordinamento giuridico, Camerico, Jovene, 1972, acentuava, à pág. 200, não ser relevante aos efeitos de direito somente o sexo psicológico, social ou biológico, mas qualquer elemento 
que concorra à sua complexa definição, embora "para a maior parte das hipóteses seja o perfil psicológico, ainda mais que o estrutural e biológico, que prevalece como critério qualificador da regulamentação das relações"

Justifica nestas condições a mudança do sexo não como expressão de livre e arbitrária escolha do interessado, mas como consequiência de terapias e de intervenções cirurgias destinadas a acompanhar uma tendência natural, ou para evitar efeitos negativos sobre a saúde, como no caso de uma grave neurose, ou sobre o comportamento da pessoa.

O problema é particularmente interessante nos países como a Itália e o Brasil que não têm legislação específica.

O Código Civil peninsular limita-se a proibir, no art. 5.', os atos de disposição do próprio corpo "quando podem ocasionar uma diminuição permanente da integridade física, ou quando sejam de outra forma contrários à lei, à ordem pública ou aos bons costumes"

Admitindo-se que tais operações não podem mais ser consideradas contrárias à ordem pública ou aos bons costumes, fica ao critério do intérprete decidir se a evolução científica impõe ou não uma ampliação do conceito de integridade física para abranger o não menos importante de integridade psíquica" Uma atitude receptícia ao conceito de que não haja alteração da integridade físico-psíquica na extirpação de órgãos que, por qualquer motivo, não correspondem à sua destinação natural, conduzirá a uma solução contrária, envolvendo o destino e a felicidade de milhares de pessoas.

A tendência em 1970 era no sentido indicado por Vincenzo Mário Palmieri, "Sesso", no vol. XVII, do Novíssimo Digesto, que considerava a posição da jurisprudência italiana conforme às "exigências jurídicas e éticas da personalidade", julgando ilícitas, ocasionalmente até criminosas, as modificações arbitrárias dos órgãos copulatórios através de uma atitude postiça (ativa ou passiva) à compenetração.

Em substância, ao cirurgião seria permitido corrigir o sexo dos pseudo-hermafroditas, contanto que se trate de uma correção que vise melhorar as características do verdadeiro sexo, não de uma intervenção que aumente a simples aparência de um sexo inexistente.

Todavia um balanço da jurisprudência ordinária revela que o decurso de um decênio modificou o panorama.

Uma questão de fato impõe-se com a força do inelutável; a existência de muitos casos de pessoas submetidas a operaçōes 
de "mudança de sexo", com ablação cirurgica dos órgãos sexuais externos, realizadas mais frequentemente no exterior, principalmente em Casablanca. Os anais da Jurisprudência registraram até um caso de auto-mutilação, exemplo bastante expressivo do estado de desespero a que são levados estes indivíduos.

Certamente serão muitos mais numerosos os casos que não chegam ao conhecimento dos Tribunais.

Diante desta situação, dois problemas se apresentam em toda a sua importância.

O primeiro é saber se uma pessoa que tenha artificialmente "mudado de sexo", pode obter do Tribunal a retificação do registro de nascimento de modo que dele possa resultar um sexo diferente daquele com o qual foi registrado.

0 art. 454 do Código Civil italiano admite a retificação dos atos de Estado Civil somente na hipótese de erro material quanto à identificação sexual, em virtude de sentença do Tribunal passada em julgado.

Os arts. 165 e 167 do Régio Decreto n.o 1.238, de 9-7-1939, Ordenamento do Estado Civil, regulam apenas "as retificações solicitadas pelo interesse público e as que dizem respeito a erros de escrita"

Mas a legitimidade constitucional destas disposições foi posta em dúvida de um tal de Lubrano de Campamorte Riccardo que, invocando os arts. $20^{\circ}$ e 24 da Constituição, solicitava fosse declarado que, contrariamente ao que resultava do seu registro de nascimento, ele agora pertencia ao sexo feminino.

$\mathrm{O}$ art. $2 .^{\circ}$ reconhece e garante os direitos invioláveis do homem, e o art. 24, na parte que interessa, admite que todos podem agir em juízo para a salvaguarda dos próprios direitos e interesses legítimos, determinando a lei as condições e os modos para a reparação dos erros judiciários.

Poderá reivindicar como direito fundamental e inviolável à identidade sexual quem, por meio de operação voluntária, tenha adquirido características do sexo oposto ao original?

Mencionado balanço enumera seis sentenças de jurisprudência ordinária que excluem a possibilidade de obter, por parte do transexual, a retificação dos registros de Estado Civil.

Três são da Corte de Cassação, Seção I, respectivamente n. ${ }^{\circ} 1847$, de 1-6-1972; 3948, de 3-12-1974 e 1236, de 7-4-1975 (Giur. Civil, 1972, I, p. 1978 e segs.; 1975, I, p. 663 segs.; Foro It. 1975 , I, p. 1687 e segs.) ; uma do Tribunal de Milão de 
2-10-1969, Nuovo Diritto, 1970, p. 272 e segs.; uma da Corte de Apelação de Bolonha de 23-1-1970, Giur. it., 1971, I, 61; e, finalmente, uma do Tribunal de Palermo, de 17-3-1972, Dir. Fam. 1972, p. 507 e segs.

Podem ser assim resumidos seus fundamentos:

a) A transformação física além de ser limitada aos órgãos sexuais externos, verificou-se somente em conseqüência de operação cirúrgica de castração com radical extirpação dos órgãos masculinos e foi sucessivamente favorecida (pelo desenvolvimento das mamas e redução do sistema pilífero), por tratamentos hormonais adequados;

b) Isto exclui que o pedido de mudança legal do sexo possa referir-se à hipótese de errado registro do sexo masculino ao momento do nascimento; ação não admitida pelo ordenamento positivo italiano a do reconhecimento legal da mudança de sexo, da modificação voluntária dos caracteres morfológicos genitais ;

c) $\mathrm{O}$ interessado deve considerar-se pertencente ao sexo masculino não só pela ausência dos órgãos femininos internos, mas também pela presença dos cromossomos que caracterizam o sexo masculino, não podendo, a psicosexualidade, orientada no sentido de atitudes mentais e interesse de tipo feminino, assurgir como elemento decisivo e determinante aos fins da individuação do sexo.

Chega pois o primeiro julgado à conclusão que:

"Não é admissível em nosso ordenamento positivo a solicitação para obter o reconhecimento de um sexo diferente daquele que resulta do registro de nascimento, não conseqüente de erro de redação do mencionado registro, mas sim, em conseqüência de uma diferente realidade sexual criada por um fato voluntário do homem, mesmo baseado em substrato psico-patológico de transexualidade."

d) A presença de uma sexualidade psíquica invertida não é suficiente para atribuir o sexo em direção ao qual a psique é orientada a um indivíduo portador desde o nascimento de caracteres sexuais primários e somáticos secundários do sexo masculino.

0 sexo como fator incidente na capacidade jurídica é qualidade natural e não modificável ao estado da ciência.

e) A consciência comum fundamenta o encontro entre pessoas de sexo diferente em índices de recognoscibilidade que exige sejam naturais, certamente recusando aos artificiais. 
f) A exigência da proteção social que nasce das relações entre os dois sexos, mesmo praticadas fora do casamento, não poderia ser considerada satisfeita com a anotação da modificação de sexo nos registros do estado civil (segundo julgado).

g) A modificação dos órgãos genitais externos, determinada por não autorizados atos de disposição do próprio corpo, e a psico-sexualidade não justificam a revisão da verificação do sexo feita ao momento do nascimento e documentada no registro civil (terceiro julgado).

h) Perante a prevalente exigência de certeza das relações jurídicas a que o sexo da pessoa dá origem nos setores público e privado, frente às imprescindíveis necessidades de uma organizada vida social inspirada nos superiores ditames do interesse público, não pode o Tribunal deixar-se levar pela piedade do fato infelizmente já consumado e atribuir reconhecimento a uma voluntária mudança de sexo que comportaria, sob o ponto de vista jurídico, a adoção do princípio inadmissível segundo - qual o indivíduo, somente para secundar suas inclinações psíquicas, seria livre de determinar o próprio sexo.

Portanto, segundo as ementas:

"Somente a mudança dos caracteres sexuais somáticos realizada na época do desenvolvimento físico do indivíduo, apoiada pela presença de caracteres sexuais cromosomáticos e gonádicos, mesmo imperfeitos, justifica a mudança de atribuição de um sexo que se revelou errônea. Da mesma maneira pode admitir-se a mudança de sexo devida a trabalho prestado pelo cirurgião a fim de ajudar o natural desenvolvimento do verdadeiro sexo do indivíduo, corrigindo imperfeições ou eventuais equívocos aparentes do sexo somático. Fora de tais hipóteses não se pode admitir a mudança de sexo pela alteração artificiosa e voluntária de caracteres sexuais masculinos mediante intervenção cirúrgica" $\left(4 .^{\circ}\right.$ julgado).

"Aos fins da atribuição a um indivíduo de um sexo diferente daquele verificado no momento do nascimento, não se pode dar relevo algum à aparência exterior de qualquer maneira criada (na hipótese, artificialmente, mediante intervenção cirúrgica)" (quinto julgado).

"Visto que a personalidade humana é, conjuntamente, psíquica e somática, não se pode falar de 
um direito ao desenvolvimento da própria personalidade psíquica em contraste com a somática. Em particular, é inadmissível seja atribuído relevo e proteção jurídica à vontade do indivíduo, dirigida a modificar a seu bel prazer, segundo as suas tendências, os caracteres somáticos sexuais primários nele definidos especialmente quando tal modificação é fundamentada na voluntária intervenção cirúrgica (sexto julgado)."

\section{E em sentido positivo}

Todavia são já mais numerosos os acórdãos (em número de 8 já compilados), que admitem a possibilidade de obter o transexual a retificação dos registros do estado civil: Tribunal de Pisa, 31-12-1968, inédito ; Corte de Apelação de Roma, Seção I Civ. 26-1-1970, Giur. pen. 1971, p. 222 e segs.; Tribunal de Pisa, 9-3-1970, Giur. it., 1971, I, p. 66 e segs. ; Corte de Apelação de Milão, 29-1-1971, Temi 1971, p. 92 e segs.; Tribunal Lucca, 17-4-1972, Giur. it., 1973, II, p. 374 e segs.; Trib. Pádua 16-7-1976, Giur. mer., 1977, I, p. 6 e segs.; Tribunal Montepulciano, 10-2-1977, Giur. mer., 1977, p. 701 e segs.; comparecimento conclusional do Procurador da República em Pisa em data de 21-1-1976, e uma sentenca do Tribunal de Taranto, de 30-6-1976, Dir. fam., 1976, p. 212 e segs., relativa a um caso de evolução natural das características sexuais, evidenciada por sucessiva intervenção cirúrgica.

Resumo dos seus fundamentos:

a) Para verificar se o interessado deve ser considerado de sexo masculino ou feminino, é preciso examinar a sua posição quer sob 0 aspecto de seus caracteres somáticos, quer da personalidade, da psique.

"Faltando às nossas leis a regulamentação jurídica de um caso como o presente, caracterizado não por um erro na determinação do sexo ao momento da redação do ato de nascimento, mas por uma diversidade existente entre uma situação surgida ao momento do nascimento e uma realidade vinda em evidência no curso da vida do indivíduo, parece certo dever-se fazer referência aos princípios gerais do direito, entre os quais está o que cada um tem direito ao reconhecimento da sua verdadeira identidade e, portanto, ao reconhecimento do sexo conforme à sua pessoa." 
A aparência externa não é a única circunstância para a atribuição do sexo. "Com o lado externo, concorre o elemento psicológico" Sendo o fator psíquico e a realidade externa interdependentes (o primeiro verifica o segundo), numa estreita simbiose, a verdadeira identidade pessoal só pode ser conforme à sua natureza feminina, vindo por esse modo a ser devolvido o equilíbrio interno entre a verdadeira natureza feminina e o reconhecido (pela lei), sexo feminino, (primeira sentença).

b) "Mudança de estado civil referente ao sexo. Coexistência de caracteres somáticos e sexuais de valor primário e de tipo masculino com outros, de importância secundária, do tipo feminino. Orientação psíquica decididamente em sentido feminino. Relevância deste último e deferimento do pedido de inscrição ao registro, no sexo feminino".

o Tribunal ficou ciente de que o prevalecimento quantitativo e qualitativo dos caracteres somáticos e biológicos do tipo masculino é contrastado, aos fins de avaliação, por uma equivocidade que diz respeito sobretudo à esfera genital, na qual a constituição anatômica não corresponde absolutamente à função biológica que os mesmos órgãos são chamados a desempenhar enquanto que não se pode não considerar a coexistência dos caracteres físicos e sexuais de tipo feminino, mesmo se os conhecimentos científicos não consentiram enquadrar a anomalia numa síndrome precisa e acertar a sua gênese.

a Corte acredita poder expressar a opinião que sejam respeitadas as opiniões expressas pelos dois colégios de consulentes e que seja atribuído ao cascinotti o sexo feminino em consideração ao fato que o prevalecimento dos caracteres físicos e sexuais ficou anulado na sua coexistência e validade para fins de uma diagnose diferencial das graves anomalias verificadas. Assim, perante os caracteres biosomáticos pertencentes a ambos os sexos e que podem ser considerados de valor equivalente, determina-se a componente psicológica unívoca no sentido da feminilidade. Portanto o complexo psicológico enquadra-se num juízo global da personalidade biopsicossomática do Cascinotti como um caso separado, não suscetível da generalização."

Determina conseqüentemente ao Oficial de Estado Civil, proceder à retificação do ato de nascimento no sentido que onde está escrito "de sexo masculino" deve-se escrever "de sexo femi- 
nino" e onde está escrito o nome "Giuliano" deve-se escrever "Giuliana" (segunda sentença, e, no mesmo sentido, a terceira).

c) São poucas as variações. De qualquer maneira merecem ser citadas as observações da quarta decisão no sentido que, ao estado atual das coisas o aparecimento dos seios, a asportação do pênis e a reestruturação dos órgãos genitais de maneira que o interessado possa ter relações sexuais só "more feminae", exclui obviamente que ele possa ser definido, em base ao exposto, com imediata certeza, indivíduo de sexo masculino.

Deve-se então, recorrer à consideração global da sua personalidade, à síntese de todos os elementos que concorrem para determinar seu "eu" e a dar-lhe a fisionomia que hoje lhe é própria (quarta decisão, e no mesmo sentido, a quinta).

d) Particularmente cerrada a refutação à tese da imutabilidade do sexo verificado no momento do nascimento, fora das hipóteses de erro e da natural evolução dos caracteres sexuais:

"Na verdade, a circunstância de que a mudança de sexo não está expressamente prevista na regulamentação das anotações e retificações dos atos de estado civil, não assume relevo decisivo a favor da tese que se critica, não tendo o rol caráter taxativo.

Prova da exatidão desta última afirmação vem da própria opinião contrária, quando admite a retificação do registro civil em caso de evolução natural dos caracteres sexuais, visto que tal situação não pode ser referida a nenhuma das espécies normativas formuladas pela lei do estado civil.

Mas, a bem considerar a referência à exigência da certeza das relações jurídicas não parece pertinente, visto que a função certificativa dos atos de estado civil não é posta em discussão em virtude do atendimento do pedido de retificação. Se, por outro lado, por certeza entende-se estabilidade no tempo das relações em que o sexo é relevante, então a argumentação aparece tautológica.

$\mathrm{Na}$ verdade, a exigência de veracidade do conteúdo dos atos de estado é mais amplamente realizada através da retificação que assegura a coincidência, embora dentro dos limites acima expostos, entre o sexo atual do interessado e aquele legal, a não ser por meio da conservação da informação originária, certamente em discordância com a realidade" 
Põe, finalmente, em relevo que a decisão do transexual de submeter-se a intervenção assume um sentido terapêutico que deixa sem fundamento as argumentações que sustentam a opinião contrária, sobre a voluntariedade da modificação dos órgãos genitais externos, como se se tratasse de um capricho do indivíduo (sexta decisão).

No mesmo sentido, as sentenças ulteriores.

\section{Situação no Brasil}

No XV Congresso Brasileiro de Urologia (novembro 1975), o cirurgião plástico Dr. Roberto Farina, expondo uma tese, exibiu um filme da sua cirurgia de reversão sexual realizada em 1971, comunicando que já havia executada em 9 pacientes de sexo masculino.

Entre as muitas reações, uma foi inesperada e rumorosa: o Ministério Público o denunciou como infrator dos art. 129, $\S 2 .^{\circ}$, inc. III do Código Penal, por ter cometido lesões corporais de natureza grave, causando perda ou inutilização de membro, sentido ou função, que comina a pena de reclusão de dois a oito anos.

Condenado, em 6-9-1978 a dois anos de reclusão, sem pena acessoria de interdição de direito, em reconhecimento aos méritos do cirurgião, e tendo obtido suspensão condicional por dois anos, sem condições especiais, foi absolvido, em superior instância, por dois votos contra um.

O crime foi negado pelo advogado da defesa: não houvera inutilização de órgão ou função, mas somente adaptação de órgão e criação de funções até então inexistentes. Além disso, a ação atribuída ao acusado servira para a saúde mental da vítima.

Enquanto o relator do processo, Octávio Ruggiero, manifestava-se pela confirmação da sentença, o segundo membro da Câmara do Tribunal, Djalma Lofrano, reconhecia que o médico havia sido impelido unicamente por propósitos curativos, sem a menor intenção de prejudicar, e no exercício regular de sua profissão, acrescentando:

"A suposta vítima, de homem só possuía os órgãos extirpados inúteis à sua destinação específica e que, no seu caso, de características psicossomáticas predominantemente femininas, facilmente perceptí- 
veis desde a primeira infância, constituíam nota de repulsa, de obsessiva inconformidade. A não ser esta verdadeira deformidade, só lhe faltariam para ser mulher, os órgãos reprodutores internos. Não se tratava de homossexual, de homem com tendências ao feminismo, em conseqüência do seu meio ambiente, de defeitos de educação, de problemas de ordem mental ou de deformação de natureza moral. Era um transexual. A cirurgia realizada pelo Dr. Roberto Farina não significava tão-somente mudança de sexo, mas recondução por motivos eminentemente terapêuticos e corretivos, ao sexo organicamente preponderante e psiquicamente exclusivo sem a menor nota de ambivalência."

\section{Será válido o casamento de quem tenha mudado artificialmente de sexo?}

E o segundo problema fundamental que nem a doutrina nem a jurisprudência se apresentam ainda preparadas para enfrentar.

A única referência que encontramos na voz dos Tribunais italianos é em sentido nítidamente negativo: Tribunal de Palermo de 17-3-1972 já referida, afirmando que a "idoneidade a contrair matrimônio com um homem decorre não do fato de ser homem com aparência de mulher, nem do comportamento mais ou menos feminino do indivíduo, mas do fato de ser mulher por natureza".

Nem se poderia esperar uma conclusão diferente de um Colégio orientado no sentido de considerar irrelevante juridicamente a modificação voluntária dos caracteres somáticos sexuais primários.

Mas se a doutrina e a jurisprudência têm tendência a reconhecer que um. ex-homem tornou-se mulher para todos os efeitos, a tal ponto que pôde obter retificação do registro civil, se admitem tacitamente todos que ele possa unir-se a pessoa de sexo diferente daquele obtido artificialmente, não se poderá negar, por uma questão de coerência, que mais cedo ou mais tarde chegará o momento de reconhecer que também o casamento será possível por maiores que ainda possam ser os preconceitos, por acaloradas que possam ser as discussões e as controvérsias. 
De qualquer maneira, nesta tempestade de opiniões divergentes, de dúvidas e mal-entendidos, uma coisa é certa : só uma orientação legislativa satisfatória e acima de qualquer raciocínio apaixonado estará em condição de permitir, com todas as cautelas necessárias, não só mudança de sexo para os transexuais, como também a retificação do registro civil, e, finalmente a possibilidade de unir-se em matrimônio.

A matéria foi considerada com agudeza por uma decisão da Corte Constitucional Federal Alemã em data de 11-10-1978, Neue Juristiche Wochenschrift, fascículo 12, p. 595 e 596, que, após ter refutado que o processo de metamorfose sexual possa ser considerado contrário aos bons costumes, e imoral uma operação que visa corrigir os genitais a fim de evitar desvantagens colaterais espirituais e físicas, acrescenta:

"Mas nem a questão conexa com a correção da inserção do sexo, pela qual o recorrente pode unir-se com um pertencente ao sexo que ele possuía anteriormente, viola o bom costume. Não são necessárias ulteriores explicações que a capacidade de gerar do homem e a capacidade de engravidar da mulher, não constituem pressuposto para contrair matrimônio.

Segundo a Lei Fundamental (art. 6,1), o matrimônio é a união do homem com a mulher para uma comunhão de visa em princípio indissolúvel (cfr. $\mathrm{E}, 10,59$ (66) NJW 1959, 1483). A formação desta comunhão correspondente às próprias idéias, é tarefa das duas pessoas que se casam. Pode ser que para o vulgo um casamento entre um transexual homem com outro homem seja contrastado ou de qualquer forma reprovado. Do ponto de vista racional não há motivos em contrário (E. 36, 146(163) NJW 1974, 454).

Acrescente-se que ao estado dos conhecimentos científicos o transexual homem não deseja relações homossexuais, mas união com parceiro heterossexual e, após uma bem sucedida operação que modifique os genitais, ele se encontra na possibilidade de ter relações sexuais normais com um parceiro homem." 